\title{
Purified natural pig immunoglobulins can substitute dietary zinc in reducing piglet post weaning diarrhoea
}

Hedegaard, Chris Juul; Lauridsen, Charlotte; Heegaard, Peter M. H.

Published in:

Veterinary Immunology and Immunopathology

Link to article, DOI:

10.1016/j.vetimm.2017.02.001

Publication date:

2017

Document Version

Peer reviewed version

Link back to DTU Orbit

Citation (APA):

Hedegaard, C. J., Lauridsen, C., \& Heegaard, P. M. H. (2017). Purified natural pig immunoglobulins can substitute dietary zinc in reducing piglet post weaning diarrhoea. Veterinary Immunology and Immunopathology, 186, 9-14. https://doi.org/10.1016/j.vetimm.2017.02.001

\section{General rights}

Copyright and moral rights for the publications made accessible in the public portal are retained by the authors and/or other copyright owners and it is a condition of accessing publications that users recognise and abide by the legal requirements associated with these rights.

- Users may download and print one copy of any publication from the public portal for the purpose of private study or research.

- You may not further distribute the material or use it for any profit-making activity or commercial gain

- You may freely distribute the URL identifying the publication in the public portal 


\section{Veterinary Immunology and Immunopathology}

2 Volume 186, April 2017, Pages 9-14

3

4 Short communication

5 Purified natural pig immunoglobulins can substitute dietary zinc in

6 reducing piglet post weaning diarrhoea

8 Chris J. Hedegaard ${ }^{a}$, Charlotte Lauridsen ${ }^{b}$, Peter M.H. Heegaard ${ }^{a}$

9 a Innate Immunology Group, Division of Vaccinology and Immunology, National

10 Veterinary Institute, Technical University of Denmark, Frederiksberg, Denmark

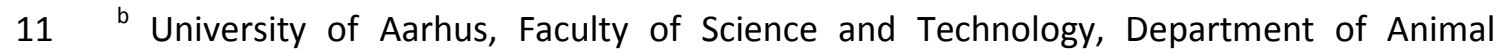

12 Science, Tjele, Denmark

13 Received 28 November 2016, Revised 1 February 2017, Accepted 3 February 2017,

14 Available online 4 February 2017

17 Abstract

18 Enteric infectious disease in weaner piglets, including postweaning diarrhoea (PWD), are

19 usually treated and/or prevented with antibiotics and/or zinc oxide in the piglet feed. 
20 However extensive use of antibiotics and zinc oxide in intensive animal production is

21 unwanted as it may promote microbial antibiotic resistance and pose environmental 22 problems. Recently, in an experimental model of PWD, we observed that oral

23 administration of purified porcine immunoglobulin $\mathrm{G}$ (pplgG) from pooled natural pig

24 plasma could reduce enteric infection. In the present study we were able to reproduce

25 these results as it was observed that oral pplgG accelerated clearance of faecal

26 haemolytic bacteria in pigs challenged with E. coli in comparison with pigs not receiving

27 pplgG. This effect was observed upon feeding pplgG for seven days postweaning

28 suggesting that pplgG does not have to be used prophylactically for several days

29 preweaning. Furthermore, the effect of oral administration of pplgG for seven days

30 postweaning was equal to or better than that of dietary zinc oxide in reducing diarrhoea

31 symptoms and in clearing faecal haemolytic bacteria for 14 days postweaning. These

32 observations warrant future trials of dietary pplgG in intensive swine production units to

33 establish its performance as an alternative to dietary antibiotics and zinc oxide for 34 preventing PWD.

35 Keywords

36 Postweaning diarrhoea; Immunoglobulins; IgG; Zinc oxide; Antibiotics; ETEC; E. coli F4;

37 Feed supplement; Feacal score

39 1. Introduction

40 After parturition, lactogenic immunity provides offspring with oro-gastric protection

41 against infectious pathogens (Hedegaard and Heegaard, 2016). In the conventional

42 swine production systems piglets are weaned at an immunologically immature age (3-4 
43 weeks) depriving them of the continued supply of protective lactogenic antibodies at the

44 same time as they are placed in a new environment with increased risk of enteric

45 bacterial infections that may lead to postweaning diarrhoea (PWD) (Madec et al., 1998).

46 PWD is characterised by diarrhoea caused by enteric infection by Enterotoxigenic

47 Escherichia coli (ETEC) usually within three days postweaning ( Fairbrother et al., 2005).

48 PWD, like other enteric infections in pigs, can be treated with dietary antibiotics

49 (primarily tetracyclines, penicillins and macrolides ( Becker, 2010; DANMAP, 2015 ;

50 Wageningen University, 2012)), and/or zinc oxide (Pluske, 2013). Indeed, antibiotics and

51 zinc can improve average daily growth (ADG) in weaner piglets ( Cromwell, 2002 ; Molist

52 et al., 2011), and dietary zinc can reduce frequency of PWD in weaner piglets ( Owusu-

53 Asiedu et al., 2003 ; Pluske, 2013). The mechanisms by which zinc oxide increases ADG

54 and reduces diarrhoea in weaner piglets are not fully understood but seem to involve

55 both restoring plasma zinc levels to normal in piglets after weaning (Davin et al., 2013)

56 and improving intestinal homeostasis ( Liu et al., 2014a; Liu et al., 2014b ; Shen et al., 57 2014).

58 However, the widespread use of dietary zinc oxide in intensive animal production can

59 result in pollution of farmlands and groundwater through repeated fertilisation with 60 zinc-containing residual manure (Hill et al., 2005). In addition, zinc oxide in combination

61 with antibiotics appears to accelerate microbial antibiotic resistance by increasing the 62 rate of the exchange of antibiotic-resistance-gene containing plasmids in the microbiota 63 community in both soil and piglet intestines (Lin et al., 2016; Pal et al., 2015 ; Vahjen et 64 al., 2015); thus, there is a need to reduce both kinds of interventions.

65 As a sustainable and economically feasible alternative to antibiotics and zinc for treating 66 PWD, we have previously investigated the use of natural purified porcine 
67 immunoglobulin G (pplgG) from pooled abattoir blood plasma (Hedegaard et al., 2016).

68 First, it was established that natural pplgG does indeed contain immunoglobulin

69 dependent anti-E. coli activity. Secondly it was shown that a dietary pplgG supplement

70 in a model of PWD led to faster clearance of an ETEC challenge infection than seen in a

71 comparable control group not provided with dietary pplgG ( Hedegaard et al., 2016).

72 This prompted us to further investigate this effect of pplgG in E.coli challenge models. A

73 long term, low pplgG dose experiment and a short term, high pplgG dose experiment

74 were performed. In both experiments dietary pplgG resulted in reduction of diarrhoea

75 and in number of faecal haemolytic bacteria; moreover, in the second trial we observed

76 that pplgG reduced diarrhoea and cleared the enteric infection faster than dietary zinc

77 oxide. These observations warrant future experiments investigating the use of dietary

78 pplgG postweaning as an alternative to dietary zinc oxide and antibiotics in

79 treating/preventing PWD.

\section{2. Materials \& methods}

82 The study comprised two infection experiments, both using E. coli $\mathrm{O} 149$ challenge at

83 two consecutive days post weaning. In experiment 1 (long term, low IgG dose pilot 84 study) $750 \mathrm{mg} /$ day of pplgG was provided orally for five days before and 10 days post weaning. In experiment 2 (short term, high IgG dose) $1.9 \mathrm{~g}$ of pplgG was given orally

86 twice daily for seven days after weaning/challenge. Experiment 2 also comprised a

87 group receiving dietary zinc oxide for 10 days after weaning.

89 2.1. Purified porcine immunoglobulin $\mathrm{G}$ (pplgG) 
90 The pplgG was prepared from pooled pig plasma by expanded bed chromatography

91 (EBA) at Upfront Chromatography A/S (Copenhagen), as described previously

92 (Hedegaard et al., 2016). Concentrated porcine blood plasma was obtained from Daka

93 SARVAL A/S (Lunderskov, Denmark). The batch of pplgG used in first experiment

94 (experiment 1, see below) was the same as in (Hedegaard et al., 2016), whereas a new

95 batch of pplgG was prepared prior to the second (experiment 2, see below).

\subsection{ELISA}

The IgG concentration in the batches of pplgG was measured by a sandwich ELISA (Hedegaard et al., manuscript in preparation), utilising a goat anti-pig $\operatorname{lgG}(\mathrm{Fc})$ antibody (AAI41, Nordic Biosite ApS, Copenhagen) both for capture and detection. The IgGconcentration of pplgG used in experiment 1 was $37.5 \mathrm{mg} / \mathrm{ml}$ and in experiment 2 the pplgG concentration was $75 \mathrm{mg} / \mathrm{ml}$.

Anti-E. coli activity was found in both batches of pplgG, used in this study, by indirect whole-E. coli cell ELISA previously reported ( Hedegaard et al., 2016); briefly 96 wells flat bottom microtiter plates (Maxisorp, NUNC, Thermo Scientific, Denmark) were coated with $100 \mu$ f fixed E. coli 0138 (in-house strain isolated from piglet with diarrhoea) in 0.1 $\mathrm{M}$ sodium carbonate buffer $\mathrm{pH} 9.6(\mathrm{OD} 546=0.25)$ at $4{ }^{\circ} \mathrm{C}$ overnight. All subsequent operations were performed at room temperature. Next day wells were washed four times in PBS with $0.05 \%$ Tween 20 (PBS-T), and blocked with $200 \mu \mathrm{l} \mathrm{PBS-T}$ with $1 \%$ bovine serum albumin (BSA; Sigma-Aldrich, Brøndby, Denmark) for 30 min when shaking

111 then followed by four times wash as above. The pplgG was added in 2-fold dilution

112 series (diluted in PBS-T $1 \%$ BSA from 10 to $0.02 \mathrm{mg} / \mathrm{ml}$ ). After $1 \mathrm{~h}$ of incubation with 113 shaking and 4 washes in PBS-T, detection antibody HRP-conjugated goat anti-pig IgG 
114 (GGHL-5P; ICL, SMS Gruppen; Rungsted, Denmark) diluted 1/2000 in PBS-T 1\% BSA was

115 added and incubated for $1 \mathrm{~h}$ with shaking. After washing, plates were developed by TMB

116 Plus substrate (Kem-En-Tec, Taastrup, Denmark), $100 \mu \mathrm{l} /$ well, and stopping colour

117 development by $100 \mu \mathrm{l} /$ well $0.5 \mathrm{M} \mathrm{H} 2 \mathrm{SO} 4$ (VWR-Bie \& Berntsen A/S). Optical density

118 was measured by a Thermo Scientific Multiscan EX microplate reader at $450 \mathrm{~nm}$

119 subtracting background absorbance at $650 \mathrm{~nm}$.

120 Using the antigen specific ELISA it was found that the pplgG batch used in experiment 1

121 had lost $14 \%$ of activity in comparison to the original plasma pool, whereas the batch

122 used in experiment 2 had lost no activity (data not shown).

2.3. Experiments

\subsubsection{Experimental procedure}

Two separate factorial experiments at Aarhus University, Foulum, involving 12 (10.8 \pm

$1271.8 \mathrm{~kg} \mathrm{BW}$, from 2 litters) and 18 (7.3 $\pm 1.0 \mathrm{~kg} \mathrm{BW}$, from 2 litters) pigs for the first and

128 second experiments, respectively, were conducted (see Table 1). In both experiments,

129 piglets were weaned from sows that had been tested to be homozygote carriers of the 130 dominant gene encoding for intestinal F4 fimbriae receptors (Van Haeringen

131 Laboratorium, b.v., Wageningen, The Netherlands) on DNA extracted from hair sample.

132 Piglets were weaned from the sows at day 28 of age, and were challenged with E. coli

133 0149:F4 on two consecutive days (d 29 and 30 of age). Within each experiment, piglets

134 from different litters were equally distributed among treatments.

135 In the first experiment, half of the piglets (Table 1; Exp. 1, Group $1+2$ ) received once 136 daily for 15 days ( 5 days preweaning and 10 days postweaning) $20 \mathrm{ml}$ (750 mg) of pplgG, 
137 provided by a $20 \mathrm{ml}$ syringe; a small plastic tube was connected to the syringe and the 138 pplgG was slowly dipped in and piglets willingly lapped up, ensuring that no pplgG was 139 lost.

140 The other half of the pigs received $20 \mathrm{ml} 0.9 \% \mathrm{NaCl}$ (Table 1; Exp. 1, Group $3+4$ ). Pigs 141 were provided the immunoglobulin product before feeding.

142 In the second experiment, pigs were allotted into three challenge-groups (Table 1; lower 143 part): two groups received no immunoglobulins but piglets were provided with $25 \mathrm{ml}$ of $1440.9 \% \mathrm{NaCl}$ and provision of feed (from day of weaning) based on wheat, barley and 145 dehulled soybean, and with either 2500 ppm zinc oxide (Hammershøj Pharmacy, 146 Hammershøj, Denmark) for 14 days postweaning (Table 1; Exp. 2, Group 1), or no zinc 147 oxide (Table 1; Exp. 2, Group 2). The third group received pplgG via $20 \mathrm{ml}$ syringe on the 148 morning before weaning (day 27), and on the morning of weaning (day 28). The pplgG 149 feeding was continued twice daily by drench gun for 7 days postweaning with a 150 provision of $25 \mathrm{ml}$ (1.9 g) of pplgG twice daily (Table 1; Exp. 2, Group 3).

152 The animal experiment was conducted according to the personal license (Charlotte 153 Lauridsen, J. nr. 2012-15-2934-00125) obtained by the Danish Animal Experiments 154 Inspectorate, Ministry of Food, Agriculture and Fisheries, Danish Veterinary and Food 155 Administration, and animals were followed by proper veterinary surveillance throughout 156 the experiment. 
159 All piglets were tested susceptible to E. coli O149:F4 by using a DNA marker genotyping-

160 based test (van Haeringen laboratorium b.v., Wageningen, The Netherlands) on DNA

161 extracted from hair samples. From weaning and onwards, the pigs had ad libitum access

162 to feed and water. The feed was a standard diet for weaners prepared at the facilities at

163 Aarhus University, Foulum. Two littermates of similar weight were housed in pairs in

$1641.45 \mathrm{~m} \times 1.7 \mathrm{~m}$ pens with concrete flooring and sawdust bedding. In experiment 1 , the

165 unchallenged (Groups $1+3$ ) and challenged pigs (Groups $2+4$ ) were housed in different

166 rooms to avoid cross contamination with the challenge E. coli strain. A door separated

167 the rooms between the challenged and unchallenged piglets, and personnel changed

168 clothes/shoes before entering any of the rooms. Environmental conditions including

169 temperature $\left(\sim 24^{\circ} \mathrm{C}\right)$, humidity $(\sim 50 \%)$ and bedding (sawdust) were similar in the two

170 rooms. Experiment 2 was conducted in the same rooms, but all pigs were challenged

171 with E. coli, and there was free passage between the rooms throughout the entire

172 experiment.

$174 \quad$ 2.3.2.1. E. coli challenge

175 In both experiments, pigs were orally inoculated with $1.0 \times 109$ colony-forming units

176 (cfu) of E. coli O149:F4 in $5 \mathrm{ml} 0.9 \% \mathrm{NaCl}$ on day 1 and 2 after weaning (day 0 was the 177 day of weaning) using a syringe. After inoculation, the tube was flushed with 178 approximately $10 \mathrm{ml} 10 \% \mathrm{NaHCO} 3$ in order to neutralize gastric acid and increase the 179 survival rate of the challenge strain in the stomach, and to ascertain that all the E. coli suspension had been given to the piglets. The control pigs (exp. 1) received equivalent 
182 an equal level of stress associated with the oral inoculation as for the challenge treatment.

186 Diarrhoea assessment was based on the consistency of the faeces ( 1 = hard, dry and 187 cloddy, 2 = firm, 3 = soft with shape, 4 = soft and liquid, 5 = watery and dark, 6 = watery and yellow, 7 = foamy and yellow) from the day prior to challenge until 7 days after. $A$ faecal consistency score $>3$ was defined as a clinical sign of diarrhoea (Carstensen et al., 2005). Before the E. coli challenge, and on day 2 after challenge, and daily until day 5 after challenge, and thereafter every second day during the second week after weaning, faecal samples were collected from the rectum of the pigs and $1 \mathrm{~g}$ faeces was suspended in a $(1: 10, \mathrm{wt} / \mathrm{wt})$ peptone solution and homogenized by bag mixer (BagMixer100, Interscience, St. Nom, France). Serial dilutions of the slurry were done prior to enumeration of haemolytic E. coli on blood agar (BA; Oxoid) after aerobic incubation at $37{ }^{\circ} \mathrm{C}$ overnight. From each BA plate, five haemolytic E. coli colonies were selected and

197 tested for 0149 and 0138 type reactions by O-seroagglutination (Statens Serum Institut, 198 Copenhagen, Denmark). In addition, faecal samples were analysed for dry matter by 199 freeze-drying (ScanVac Coolsafe 55, Labogene Aps, Lynge, Denmark).

200 Feed intake was recorded daily for each pen and body weight of the pigs was recorded 201 at the beginning and weekly thereafter until the end of the experiment. Average daily 202 feed intake (ADFI) and gain (ADG) were determined based on pen by dividing the total 203 feed intake or total weight gain of pigs in each pen by days of feeding. 
206 The effects of pplgG, dietary zinc oxide or no treatment for seven days postweaning on

207 diarrhoea symptoms and bacterial count in both experiments were statistically analysed

208 using either Mann-Whitney test or Two-way ANOVA followed by Tukey's post-test, in

209 GraphPad Prism version 7.00 for Windows, GraphPad Software, La Jolla California USA,

210 www.graphpad.com.

\section{Results and discussion}

213 In this study we performed two infection experiments using an E. coli 0149 challenge

214 strain at both day one and two after weaning. The administration of pplgG was different

215 in the two experiments: In experiment 1, $750 \mathrm{mg}$ of pplgG was provided orally once daily

216 prophylactically for five days preweaning and then 10 days postweaning, whereas in

217 experiment 2, $1.9 \mathrm{~g}$ of pplgG was administered orally twice daily for seven days

218 postweaning. Two different pplgG batches were used for the two experiments, for experiment 1 a $37.5 \mathrm{mg} / \mathrm{ml}$ batch and for experiment 2 a $75 \mathrm{mg} / \mathrm{ml}$ batch.

\subsection{Disease}

In both experiments diarrhoea was observed within one day after inoculation due to the

223 O149 ETEC challenge as observed by faecal scoring (Fig. 1A + B) and faecal dry matter measurement (Fig. 1C + D). We observed in both experiments that the +pplgG +challenge group (group 2 in exp. 1 and group 3 in exp. 2) had, at day five, significantly less diarrhoea as compared to the control challenge groups (group 4 in exp. 1 and group 
2272 in exp. 2) that were not provided with pplgG as observed by a lower faecal scoring and

228 a higher percentage of faecal dry matter ( $p<0.03$; Fig. 1, days $1-5)$. In experiment 1 the

2290149 ETEC challenge strain began to cease at day 7, however an unintended enteral

230 infection, starting around day 5-7 after weaning and lasting the remainder of the study

231 period was observed (Fig. 1A + C, days 5-21), coinciding with the appearance of an 0138

232 ETEC strain in faeces (detected by PCR; data not shown). The presence of this

233 unintended infection somewhat obscured experiment 1 , however the data from day 0 to

234 five were promising and prompted us to conduct a second experiment in which the daily

235 IgG dose was quadrupled but then only provided seven days post weaning. This batch of

236 pplgG had an IgG concentration of $75 \mathrm{mg} / \mathrm{ml}$, and was administered twice daily,

237 amounting to a daily dose of $3.8 \mathrm{~g}$.

238 Experiment 2 proceeded without any unintended infection, and group 3 (+pplgG

239 +challenge group) had significantly less diarrhoea than both group 1 and 2 (+zinc

240 +challenge and no treatment groups) within the first week after weaning $(p<0.02$ Two-

241 way ANOVA; Fig. 1B + D); demonstrating that pplgG significantly reduced diarrhoea in

242 the PWD model within the first week post weaning to the same level or lower than

243 dietary zinc.

244 Moreover, our results indicate that it is not necessary to use pplgG prophylactically for

245 several days preweaning as there was a clear effect of pplgG in experiment 2 on

246 diarrhoea without the five days preweaning pplgG treatment applied in experiment 1

247 (Fig. 1). This also corroborates a previous study (Hedegaard et al., 2016) where pplgG

248 was mixed into the feed that was only available from weaning and decreased

249 diarrhoeagenic Enterobacteriaceae in comparison to a non-pplgG diet. Also, it has been

250 shown (Foged et al., 1986) that monoclonal anti-E. coli F4 fimbriae antibodies 
administered at as well as after challenge, but not prophylactically, protected neonatal piglets from an otherwise lethal challenge with F4+ ETEC. On the other hand, it seems to be important to maintain a high administration frequency and an adequately high antibody dose for limiting diarrhoea.

In both experiments pplgG helped clear the challenge strain within one week of challenge (Fig. 2, days 1-7). However, as noted above, all groups in experiment 1 experienced an unintended 0138 ETEC infection from day 4-9, as seen by an increase in numbers of faecal haemolytic bacteria (Fig. $2 A$, days $4+7+9)$. Group 1 (+pplgG no challenge) experienced this infection at day 4 while it was observed in group $2(+p p l g G$ +challenge) on day 9. Thus, the daily administration of $750 \mathrm{mg}$ of natural IgGs did not provide protection against the unintended infection in neither of the two +pplgG groups (Fig. 2A, groups $1+2$, days $4-21$ ), even though in vitro data support that pplgG binds to O138 (and O149) ETEC and can inhibit their adhesion to intestinal epithelial cells in vitro ( Hedegaard et al., 2016). This might indicate that the unintended infection was multifactorial, and/or that the daily dose of $750 \mathrm{mg}$ natural pplgG used in this experiment was not adequate to prevent this type of infection. Data from doseresponse field trials are needed before any further conclusions can be made on this matter.

271 In experiment 2, only infection with the challenge-strain was observed. Confirming 272 previous results (Hedegaard et al., 2016), pplgG caused a faster clearance of 273 diarrhoeagenic (haemolytic) bacteria in group 3 than was observed in the other two 274 groups (Fig. 2B). Thus day 7 was the last day on which faecal haemolytic bacteria were 
detected in group $3(+p p \lg )$, while these bacteria could still be detected on day 9 in group 1 (+zinc group), and in group 2 (control) one piglet still had faecal haemolytic bacteria on day 15 (Fig. 2B). Taken together, pplgG appears to intervene with the colonization by the ETEC challenge strain shortening the period of infection significantly (Fig. 2B, Day $5, p<0.02$ ) and was as efficient as dietary zinc in reducing the infection with the ETEC challenge strain. Although this suggests that pplgG can shorten the duration of diarrhoea in weaner piglets by decreasing the number of faecal diarrhoeagenic haemolytic bacteria, this should ideally take place without a perturbing the composition of the normal intestinal microbiota. In experiment 1 , no change in the faecal non-haemolytic bacteria were initially observed (Fig. 2C, days 1-5) however, as the unintended infection emerged the number of faecal non-haemolytic bacteria began decreasing (Fig. 2C, days 7-21). In group 2 (+pplgG +challenge) the faecal nonhaemolytic bacteria actually were not recovered for 3 days at the height of the unintended infection (Fig. 2C, days 11-14), which coincided with the termination of administration of pplgG. However in experiment 2, no changes in the count of faecal non-haemolytic bacteria in any of the three other groups were observed (Figs. 2D), indicating that pplgG does not intervene with the intestinal non-haemolytic commensal microbiota and that the microbiota changes observed in experiment 1 was probably due to the unintended infection. These observations are supported by preliminary next generation sequencing data on the faecal microbiota composition of piglets fed pplgG showing no change in non-haemolytic commensals (unpublished data).

Disease (diarrhoea) frequency, growth and feed conversion are primary end points for swine producers however the two experiments described here comprised low numbers of piglets $(n=12 / 18)$ and pens $(n=4 / 3)$ making it very difficult to analyse growth data statistically. Also, the data on growth and feed intake showed a very large pig-to-pig 
300 variation. For example, in experiment 2 half of the piglets in group $3(+p p l g G)$, for

301 unknown reasons, became anorexic during the third week resulting in almost no weight

302 gain for the group. Therefore it will be interesting to observe how pplgG

303 supplementation will influence disease resistance, growth and feed conversion in field

304 trials incorporating an adequate number of pigs to allow for appropriate statistical data

305 analysis to be performed. In spite of being a small preliminary study the results shown

306 here do however demonstrate the ability of dietary pplgG to clear an enteric ETEC

307 infection and thus pplgG could be used as an alternative to dietary zinc.

\section{Acknowledgements}

310 The project was supported by Green Development and Demonstration Programme

311 (Ministry of Food, Agriculture and Fisheries, The Danish AgriFish Agency, Journal 312 number: 34009-12-0471). Henriette Vorsholt is thanked for excellent technical 313 assistance with the laboratory analysis and Inger Marie Jepsen is thanked for excellent 314 technical assistance during the animal experiments. 
322 Becker, 2010

323 G.S. Becker

324 Antibiotic Use in Agriculture: Background and Legislation

325 Congressional Research Service, MA, USA (2010)

326

327 Carstensen et al., 2005

328 L. Carstensen, A.K. Ersboll, K.H. Jensen, J.P. Nielsen

329 Escherichia coli post-weaning diarrhoea occurrence in piglets with monitored exposure

330 to creep feed

331 Vet. Microbiol., 110 (2005), pp. 113-123

332

333 Cromwell, 2002

334 G.L. Cromwell

335 Why and how antibiotics are used in swine production

336 Anim. Biotechnol., 13 (2002), pp. 7-27

337

338 DANMAP, 2015

339 DANMAP, 
341 National Food Institute, Søborg, Denmark (2015)

342

343 Davin et al., 2013

344 R. Davin, E.G. Manzanilla, K.C. Klasing, J.F. Perez

345 Effect of weaning and in-feed high doses of zinc oxide on zinc levels in different body

346 compartments of piglets

347 J. Anim. Physiol. Anim. Nutr. (Berl), 97 (Suppl. 1) (2013), pp. 6-12

348

349 Fairbrother et al., 2005

350 J.M. Fairbrother, E. Nadeau, C.L. Gyles

351 Escherichia coli in postweaning diarrhea in pigs: an update on bacterial types, pathogenesis, and prevention strategies

353 Anim. Health Res. Rev., 6 (2005), pp. 17-39

354

355 Foged et al., 1986

356 N.T. Foged, P. Klemm, F. Elling, S.E. Jorsal, J. Zeuthen

357 Monoclonal antibodies to K88ab, K88ac and K88ad fimbriae from enterotoxigenic $358 \quad$ Escherichia coli 
Passive immunisation, an old idea revisited: basic principles and application to modern

364 animal production systems

365 Vet. Immunol. Immunopathol., 174 (2016), pp. 50-63

367 Hedegaard et al., 2016

368 C.J. Hedegaard, M.L. Strube, M.B. Hansen, B.K. Lindved, A. Lihme, M. Boye, P.M. 369 Heegaard

370 Natural pig plasma immunoglobulins have anti-Bacterial effects: potential for use as

371 feed supplement for treatment of intestinal infections in pigs

372 PLoS One, 11 (2016), p. e0147373

374 Hill et al., 2005

375 D.D. Hill, W.E. Owens, P.B. Tchoounwou

376 Impact of animal waste application on runoff water quality in field experimental plots 
379 Lin et al., 2016

380 H. Lin, W. Sun, Z. Zhang, S.J. Chapman, T.E. Freitag, J. Fu, X. Zhang, J. Ma

381 Effects of manure and mineral fertilization strategies on soil antibiotic resistance gene

382 levels and microbial community in a paddy-upland rotation system

383 Environ. Pollut., 211 (2016), pp. 332-337

384

385 Liu et al., 2014a

386 P. Liu, R. Pieper, J. Rieger, W. Vahjen, R. Davin, J. Plendl, W. Meyer, J. Zentek

387 Effect of dietary zinc oxide on morphological characteristics, mucin composition and 388 gene expression in the colon of weaned piglets

389 PLoS One, 9 (2014), p. e91091

390

391 Liu et al., 2014b

392 P. Liu, R. Pieper, L. Tedin, L. Martin, W. Meyer, J. Rieger, J. Plendl, W. Vahjen, J. Zentek

393 Effect of dietary zinc oxide on jejunal morphological and immunological characteristics 394 in weaned piglets

395

J. Anim. Sci., 92 (2014), pp. 5009-5018 
400 Prev. Vet. Med., 35 (1998), pp. 53-72

401

402

Molist et al., 2011

403

F. Molist, R.G. Hermes, A.G. de Segura, S.M. Martin-Orue, J. Gasa, E.G. Manzanilla, J.F.

404 Perez

405 Effect and interaction between wheat bran and zinc oxide on productive performance 406 and intestinal health in post-weaning piglets

407 Br. J. Nutr., 105 (2011), pp. 1592-1600

408

409 Owusu-Asiedu et al., 2003

410 A. Owusu-Asiedu, C.M. Nyachoti, R.R. Marquardt

411 Response of early-weaned pigs to an enterotoxigenic Escherichia coli (K88) challenge

412 when fed diets containing spray-dried porcine plasma or pea protein isolate plus egg

413 yolk antibody, zinc oxide, fumaric acid, or antibiotic

414 J. Anim. Sci., 81 (2003), pp. 1790-1798 
418 Co-occurrence of resistance genes to antibiotics, biocides and metals reveals novel 419 insights into their co-selection potential

420 BMC Genomics, 16 (2015), p. 964

421

422

Pluske, 2013

423

J.R. Pluske

424 Feed-and feed additives-related aspects of gut health and development in weanling pigs

425 J. Anim. Sci. Biotechnol., 4 (2013), p. 1

426

427

Shen et al., 2014

428 J. Shen, Y. Chen, Z. Wang, A. Zhou, M. He, L. Mao, H. Zou, Q. Peng, B. Xue, L. Wang, X. 429 Zhang, S. Wu, Y. Lv

430 Coated zinc oxide improves intestinal immunity function and regulates microbiota 431 composition in weaned piglets 
436 W. Vahjen, D. Pietruszynska, I.C. Starke, J. Zentek

437 High dietary zinc supplementation increases the occurrence of tetracycline and 438 sulfonamide resistance genes in the intestine of weaned pigs

439 Gut Pathog., 7 (2015), p. 23

440

441 Wageningen University, 2012

442 Wageningen University

443 Antibiotic Usage in Pigs

444 Wageningen University \& Research (2012) (Wageningen, Netherlands,

445 http://www.wur.nl/en/Research-Results/Projects-and-programmes/MARAN-Antibiotic-

446 usage/Trends-in-use-per-species/Antibiotic-usage-in-pigs.htm) 


\begin{tabular}{|c|c|c|c|c|}
\hline Experiment 1 & $\begin{array}{l}\text { Group } 1 \\
+ \text { pplgG }\end{array}$ & $\begin{array}{l}\text { Group } 2 \\
+ \text { pplgG }+ \text { E.coli }\end{array}$ & $\begin{array}{l}\text { Group } 3 \\
\text { Control }\end{array}$ & $\begin{array}{l}\text { Group } 4 \\
+ \text { E.coli }\end{array}$ \\
\hline Number of piglets & 3 & 3 & 3 & 3 \\
\hline E. coli $\mathrm{F} 4+$ challenge & No & Yes & No & Yes \\
\hline 750 mg pplgG $(20 \mathrm{ml})$ & Yes & Yes & No & No \\
\hline $20 \mathrm{ml} 0.9 \% \mathrm{NaCl}$ solution & No & No & Yes & Yes \\
\hline $\begin{array}{l}\text { Avg. weight at weaning } \\
\text { (kg) }\end{array}$ & $11.2 \pm 3.1$ & $10.6 \pm 1.7$ & $10.4 \pm 1.9$ & $11.0 \pm 1.2$ \\
\hline Experiment 2 & $\begin{array}{l}\text { Group } 1 \\
+ \text { E.coli }+Z n\end{array}$ & $\begin{array}{l}\text { Group } 2 \\
+ \text { E.coli }\end{array}$ & $\begin{array}{l}\text { Group } 3 \\
+ \text { E.coli +pplgG }\end{array}$ & \\
\hline Number of piglets & 6 & 6 & $6(5)^{1}$ & \\
\hline E. coli $\mathrm{F} 4+$ challenge & Yes & Yes & Yes & \\
\hline $2 \times 1.9$ g pplgG $(2 \times 25 \mathrm{ml})$ & No & No & Yes & \\
\hline $25 \mathrm{ml} 0.9 \% \mathrm{NaCl}$ solution & Yes & Yes & No & \\
\hline Zinc oxide in feed & Yes & No & No & \\
\hline $\begin{array}{l}\text { Avg. weight at weaning } \\
\text { (kg) }\end{array}$ & $6.9 \pm 1.1$ & $7.9 \pm 0.9$ & $7.0 \pm 0.9$ & \\
\hline
\end{tabular}

${ }^{1}$ One piglet was euthanized on day 3 post infection due to serious illness. 
460 Figure 1. Faecal analysis: Faecal diarrhoea score (A+B) and faecal dry matter (C+D);

461 no treatment, no E. coli; ( $\bullet$ ) no treatment, +E. coli: $(--)+p p l g G$, no E. coli; ( $\triangle$ )pplgG

462 treatment, +E. coli; ( $\square$ ) dietary zinc, +E. coli. Each data point is plotted and curves

463 outline the mean for each group. Vertical dotted line indicates the last day of pplgG

464 administration. Pairwise comparisons between groups on each day were tested for 465 statistical significance using Mann-Whitney test: $a=\operatorname{IgG}$ vs. Zinc $(p<0.03) ; b=\operatorname{IgG}$ vs. 466 Control $(p<0.03) ; c=\operatorname{IgG}$ vs. Zinc $(p<0.02) ; d=\lg$ vs. Control $(p<0.01) ;$ e = Zinc vs. 467 Control $(p<0.02)$.

Figure 2. Faecal bacterial analysis: Content (CFU/ml) of haemolytic bacteria (A+B) and non-haemolytical bacteria (C+D). Symbols as for Figure 1. Each data point is plotted and curves outline the mean for each group. Vertical dotted line indicates the last day of pplgG administration. Pairwise comparisons between groups on each day were tested for statistical significance using Mann-Whitney test: $a=\lg G$ vs. control $(p<0.02)$. 

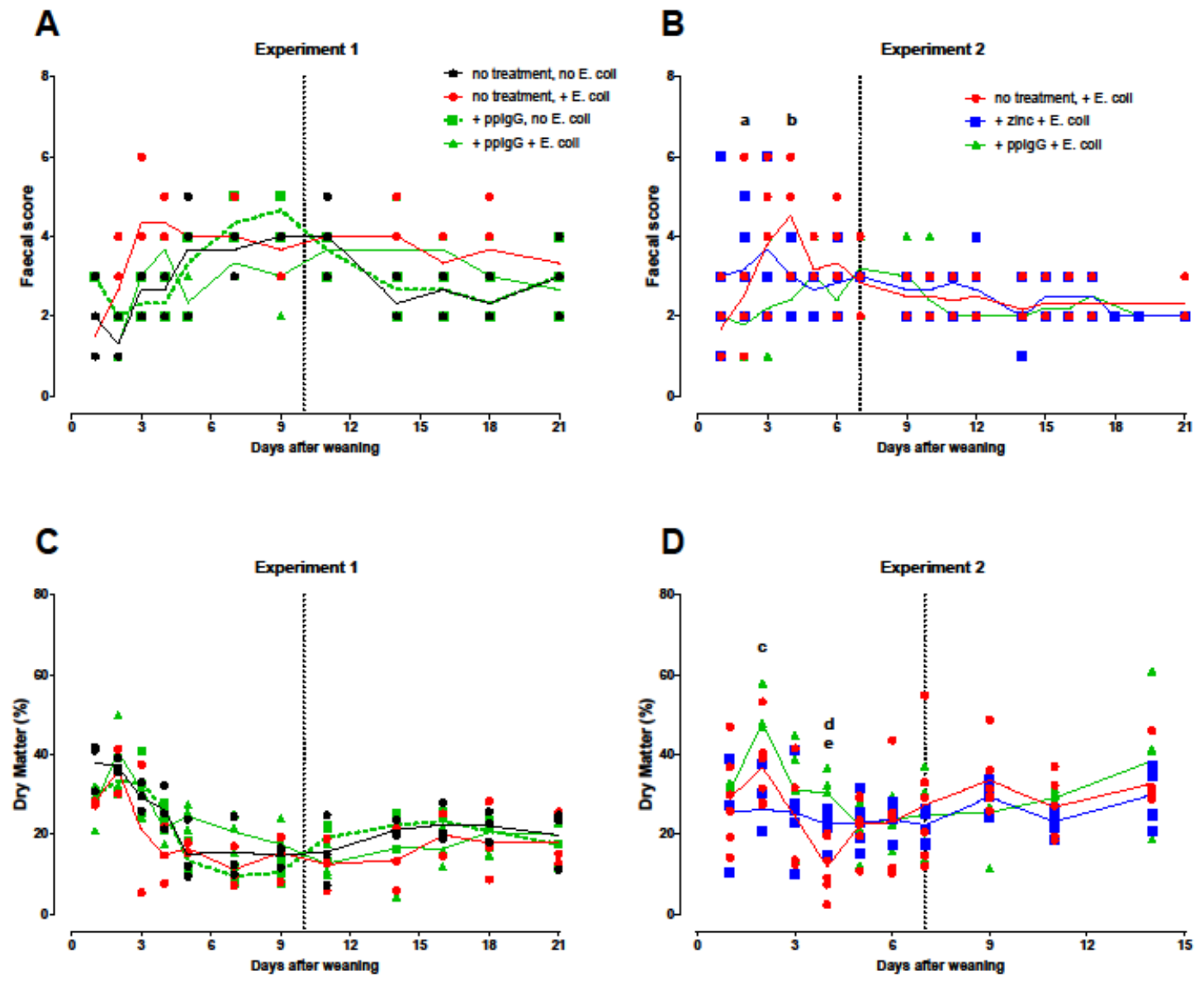

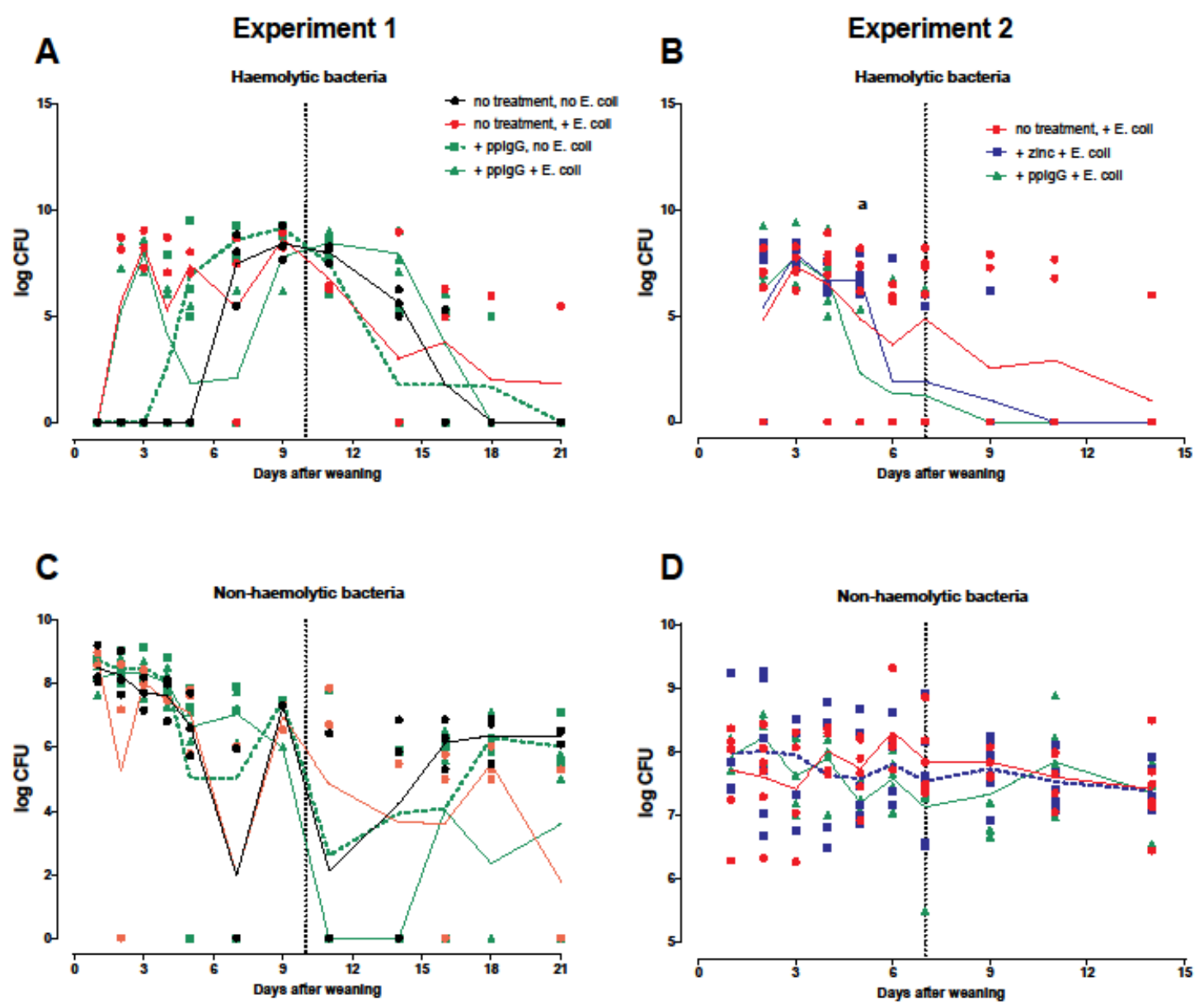